\title{
A $\beta-1,3$ Glucan Sulfate Induces Resistance in Grapevine against Plasmopara viticola Through Priming of Defense Responses, Including HR-like Cell Death
}

\author{
S. Trouvelot, ${ }^{1}$ A.-L. Varnier, ${ }^{2}$ M. Allègre, ${ }^{1}$ L. Mercier, ${ }^{3}$ F. Baillieul, ${ }^{2}$ C. Arnould, ${ }^{1}$ V. Gianinazzi-Pearson, ${ }^{1}$ \\ O. Klarzynski, ${ }^{4}$ J.-M. Joubert, ${ }^{4}$ A. Pugin, ${ }^{1}$ and X. Daire ${ }^{1}$ \\ ${ }^{1}$ Unité Mixte de Recherches INRA-CNRS-Université de Bourgogne, Plante-Microbe Environnement, INRA, 17 Rue Sully, \\ BP 86510, 21065 Dijon cedex, France; ' 2 Laboratoire de Stress, Défenses et Reproduction des Plantes. Faculté de Sciences \\ Exactes et Naturelles, Moulin de la Housse, BP 1039, 51687 Reims cedex 2, France; ${ }^{3}$ Moët et Chandon, 6 Rue Croix \\ de Bussy, 51200 Epernay, France; ${ }^{4}$ Laboratoires Goëmar, Avenue du Général Patton, 35400 Saint-Malo, France
}

Submitted 13 June 2007. Accepted 25 October 2007.

\begin{abstract}
Sulfated laminarin (PS3) has been shown previously to be an elicitor of plant defense reactions in tobacco and Arabidopsis and to induce protection against tobacco mosaic virus. Here, we have demonstrated the efficiency of PS3 in protecting a susceptible grapevine cultivar (Vitis vinifera cv. Marselan) against downy mildew (Plasmopara viticola) under glasshouse conditions. This induced resistance was associated with potentiated $\mathrm{H}_{2} \mathrm{O}_{2}$ production at the infection sites, upregulation of defense-related genes, callose and phenol depositions, and hypersensitive response-like cell death. Interestingly, similar responses were observed following $P$. viticola inoculation in a tolerant grapevine hybrid cultivar (Solaris). A pharmacological approach led us to conclude that both callose synthesis and jasmonic acid pathway contribute to PS3-induced resistance.
\end{abstract}

Grapevine (Vitis vinifera L.) is a perennial crop species that is sensitive to a large spectrum of pathogens. Downy mildew, caused by Plasmopara viticola (Berk. \& M. A. Curtis) Berl. \& de Toni, is an important disease in many of the world's viticultural areas. $P$. viticola is a biotrophic organism belonging to the Oomycetes, family Peronosporaceae. The pathogen attacks all green parts of the grapevine. In susceptible genotypes (all $V$. vinifera cultivars), downy mildew can develop and spread rapidly during a single season. When conditions favor pathogen infection (wet weather), its control requires frequent fungicide applications to prevent significant crop losses. However, growing concern about the impact of pesticides on the environment is motivating research for alternative strategies to control grape diseases, including activation of defense. This latter relies on the application of inducers of resistance, also called elicitors, which mimic pathogen attack. Recognition of the invader is mediated via perception of elicitor molecules released during the interaction, which subsequently activate a battery of defense reactions, including both chemical and physical defense responses (Garcia-Brugger et al. 2006; Sheel 1998). These comprise the accumulation of host-synthesized phytoalexins, deposition of phenolics, lignin or callose-like materials, increased activity of pathogenesis-related (PR) proteins with hydrolytic activity (e.g., chitinases and glucanases)

Corresponding author: Xavier Daire; Telephone: +33 3806931 04; Fax: +33 3806932 26; E-mail: daire@dijon.inra.fr and, often, hypersensitive response (HR). Altogether, these reactions reduce pathogen growth.

Elicitors are found in various biochemical families (that is, carbohydrates, lipids, and proteins) corresponding to inducers now referred to as pathogen- or microbial-associated molecular patterns (MAMP) (Jones and Dangl 2006).

In the case of grapevine, it recently was reported that endopolygalacturanase 1 (BcPG1) of Botrytis cinerea induces defense-related responses, which include ion fluxes, mitogenactivated protein kinase activation, $\mathrm{NO}$ and $\mathrm{H}_{2} \mathrm{O}_{2}$ production, defense genes transcripts accumulation, and phytoalexin synthesis (Poinssot et al. 2003; Vandelle et al. 2006). Oligosaccharides derived from microbes, algae, or plant cell walls are also well-known MAMP (Albersheim and Darvill 1985; Côté and Hahn 1994; Nürnberger et al. 2004). Among them, $\beta-1,3$ glucans have been shown to be potent elicitors of defense responses in various plants (Côté et al. 1998; Sharp et al. 1984). Laminarin, a linear $\beta-1,3$ glucan (degree of polymerization approximately 33) extracted from the brown algae Laminaria digitata, triggered defense responses and induced resistance in tobacco against the soft rot pathogen Erwinia carotovora (Klarzynski et al. 2000). In a similar manner, Aziz and associates (2003) found that this glucan was an effective elicitor in reducing downy mildew $(P$. viticola) and gray mould $(B$. cinerea) infection of grapevine.

The compound obtained by chemical sulfation of laminarin, PS3, was found to elicit a wider array of defense responses in tobacco and Arabidopsis than the native compound (Ménard et al. 2004). This broader activity was associated with enhanced induced resistance against Tobacco mosaic virus (TMV) in tobacco. In the same study, it was demonstrated that the sulfate residues and a minimum $\beta-1,3$ glucan chain length are essential for PS3 activity. Here, we show that PS3 also induces resistance of grapevine against $P$. viticola. This resistance is associated with $\mathrm{H}_{2} \mathrm{O}_{2}$ production, upregulation of defense-related genes, and cytological changes, including phenol deposition, cytoplasmic disorganization, and localized plant and pathogen cell death, occurring specifically in cells invaded by the parasite structures. We found that PS3-induced defenses were similar to those occurring in a naturally tolerant hybrid grapevine in response to $P$. viticola inoculation. Interestingly our data indicate that a foliar pretreatment with PS3 potentiates the defense responses in grapevine. Finally, experiments with specific inhibitors suggested that callose deposition and the jasmonic acid (JA) pathway both contribute to PS3-induced resistance (PS3-IR). 


\section{RESULTS}

PS3 induces resistance in grapevine against $P$. viticola.

In order to check the capacity of PS3 to protect grapevine against $P$. viticola, the leaves of plants were sprayed once with a PS3 solution in an appropriate surfactant and inoculated with $P$ viticola 2 days later.

Foliar pretreatment of the Marselan susceptible cultivar with PS3 reduced development of $P$. viticola and disease severity in a dose-dependent manner (Fig. 1). Sporulating area was reduced by $57 \%$ at $1.25 \mathrm{mg} \cdot \mathrm{ml}^{-1}$ and $85 \%$ at $5 \mathrm{mg} \cdot \mathrm{ml}^{-1}$. The surfactant alone had no significant effect on disease severity (not shown).

\section{PS3 has no direct effect}

\section{on $P$. viticola sporangia and zoospores.}

To determine whether PS3 could act as a fungitoxic or fungistatic product, we estimated i) the viability of $P$. viticola sporangia after incubation in the PS3 solution and ii) the ability of the pathogen to colonize the host tissues when inoculated rapidly after PS3 treatment (i.e., before defense reactions were fully activated).

After 10 min of incubation, PS3 or its surfactant had no effect on sporangia viability when compared with water treatment (data not shown). Longer incubation periods could not be tested because, with time, maturation of sporangia occurred and they started to release zoospores.

Further, when inoculated $4 \mathrm{~h}$ after PS3 treatment, $P$. viticola colonization of leaf disks and sporulation was similar to that of the untreated control (data not shown). These results suggest that PS3 has no significant direct toxic effect against zoospores.

\section{PS3 reduces $P$. viticola development in foliar tissues of treated susceptible grapevine.}

To monitor the pathogen growth in leaves treated or not by PS3, foliar disks were sampled at different time points postinoculation and the presence of the pathogen was revealed after aniline blue staining and epifluorescence observations.

Until 2 days postinoculation (dpi), no differences in $P$. viticola development were detectable between control and PS3-treated leaves. At $1 \mathrm{dpi}$, encysted zoospores were observed regularly in stomata over the leaf surface and, at 2 dpi, hyphae had developed with haustoria in contact with mesophyll cells (not shown). The first differences between control and PS3-treated leaves became obvious at $3 \mathrm{dpi}$. In control samples, aniline blue staining showed branched hyphae growing evenly through the leaf (within intercellular spaces) (Fig. 2A), whereas fungal spread was reduced in PS3-treated samples (Fig. 2B.1). In addition, the structures of the pathogen appeared altered in some zones (Fig. 2B.2). P. viticola showed extensive growth in control samples at 5 dpi (Fig. 2C). This stage coincided with the appearance of typical "oil spot" symptoms on the adaxial side of the leaf. At the same time point, colonization was restricted in PS3-treated samples and large, uninfected areas were visible adjacent to colonized zones (Fig. 2D.1). Strongly fluorescent aniline blue-stained stomata often were observed in pathogenfree areas of PS3-treated leaves (Fig. 2D.2). Finally, at 7 dpi of control plants, extensive colonization of leaf tissues was followed by the abundant formation of sporangiophores, passing through stomata (Fig. 2E), whereas sporulation was totally absent in infected areas of PS3-treated plants (Fig. 2F). This effect of PS3 treatment on $P$. viticola sporulation was confirmed by scanning electron microscopy showing aborted sporangiophores, deprived of sporangia emerging through stomata (Fig. 3B.1). At the opposite extreme, in control plants, full sporangiophores developed (Fig. 3A). PS3-treated areas adjacent to those infected by the pathogen presented stomata with secretions (Fig. 3B.2) which plugged the ostiole (Fig. 3B.3). These observations led us to conclude that PS3 treatment induced a strong restriction of mesophyll colonization by $P$. viticola and that this was associated with callose deposition.

\section{PS3 primes $\mathrm{H}_{2} \mathrm{O}_{2}$ production in leaf tissues of treated inoculated plants.}

The NADPH oxidase-dependent $\mathrm{H}_{2} \mathrm{O}_{2}$ production is a wellknown host response (Pugin et al. 1997) and could be involved in grapevine resistance and deleterious effect against $P$. viticola triggered by PS3. Grapevine plants were treated or not by PS3 and, 2 days posttreatment, inoculated or not by $P$. viticola. At different time points after inoculation, leaves were analyzed for $\mathrm{H}_{2} \mathrm{O}_{2}$ production using 3,3-diaminobenzidine (DAB).

Veins of control and PS3-treated leaves stained reddish-brown after DAB treatment. This probably was due to the lignification process (Olson and Varner 1993). This observation (Fig. 4A and B) confirms DAB absorption by the leaf tissues. No staining was detectable in other foliar tissues in healthy, PS3-treated or untreated leaves (Fig. 4A, D, and E). No staining appeared in untreated inoculated samples (Fig. 4B), although $P$. viticola developed abundantly, as shown by aniline blue staining (Fig. 4C). In contrast, DAB deposits could be clearly observed at 12 and 24 hpi (not shown) and at 3 dpi in inoculated PS3-treated samples. These were spread patchily throughout the leaf surface, occurring first in guard cells, then in epidermal and parenchymal cells (Fig. 4F, G, and $\mathrm{J}$ ). The observation that $P$. viticola grew normally in zones without DAB staining (Fig. $4 \mathrm{H}$ and I), whereas it appeared misshapen and altered in extensively stained zones (Fig. 4J and $\mathrm{K}$ ), suggests a possible relationship between $\mathrm{H}_{2} \mathrm{O}_{2}$ production and hyphal degenerescence in PS3treated plants. DAB staining also was observed in pathogeninoculated leaves of the tolerant cv. Solaris when inoculated with $P$. viticola (Fig. 4M and N), with a pattern similar to that of PS3treated Marselan. Thus, $\mathrm{H}_{2} \mathrm{O}_{2}$ production is limited to PS3treated inoculated plants and particularly to invaded zones. The concomitant presence of $\mathrm{H}_{2} \mathrm{O}_{2}$ and altered oomycete structures suggested that $\mathrm{H}_{2} \mathrm{O}_{2}$ participates to oomycete restriction.

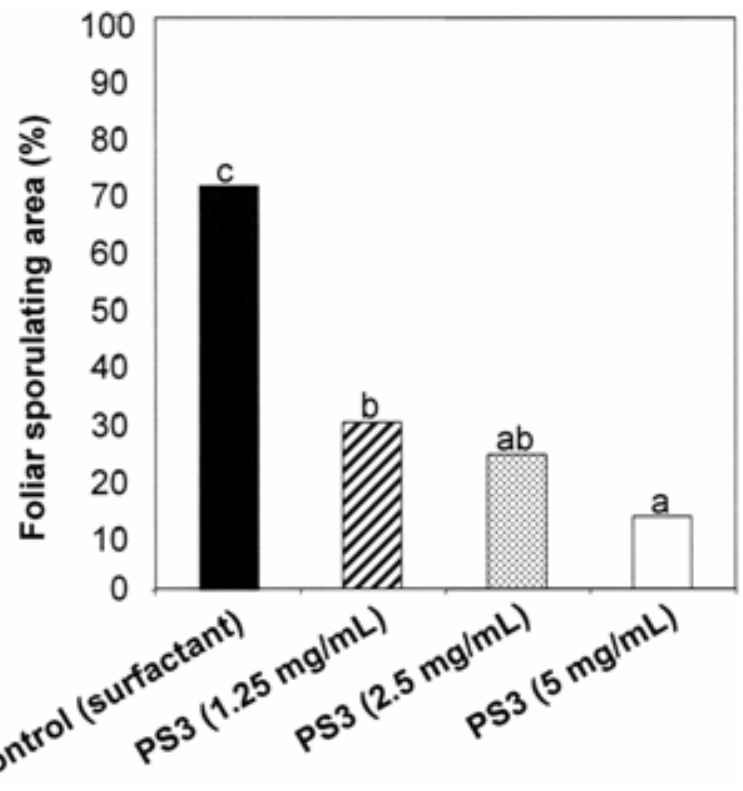

Fig. 1. Induced resistance in grapevine following PS3-treatment. Leaf area infected by Plasmopara viticola (in percent) was assessed, based on sporulation symptoms, on susceptible grapevine plants (cv. Marselan) after treatment with surfactant alone (control) or a surfactant solution containing PS3 at $1.25,2.5$, or $5 \mathrm{mg} . \mathrm{ml}^{-1}$. Values are the mean estimation for leaves noted in a same treatment from 18 cuttings (six pots per condition, three independent experiments). Means with a same letter are not significantly different at $P=0.05$. 
3 dpi
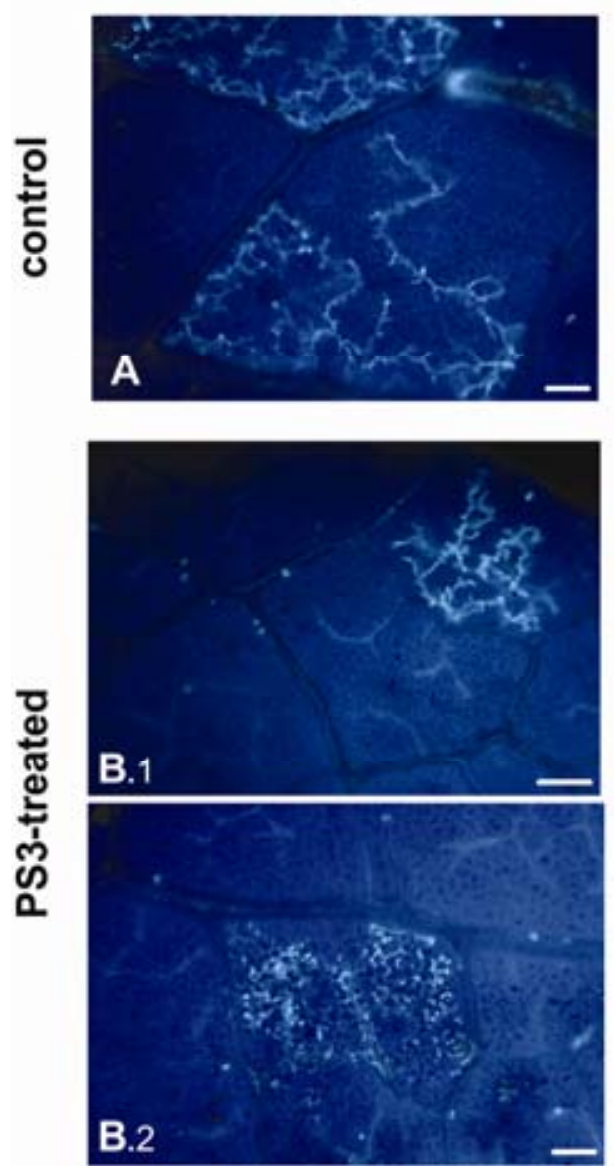

5 dpi
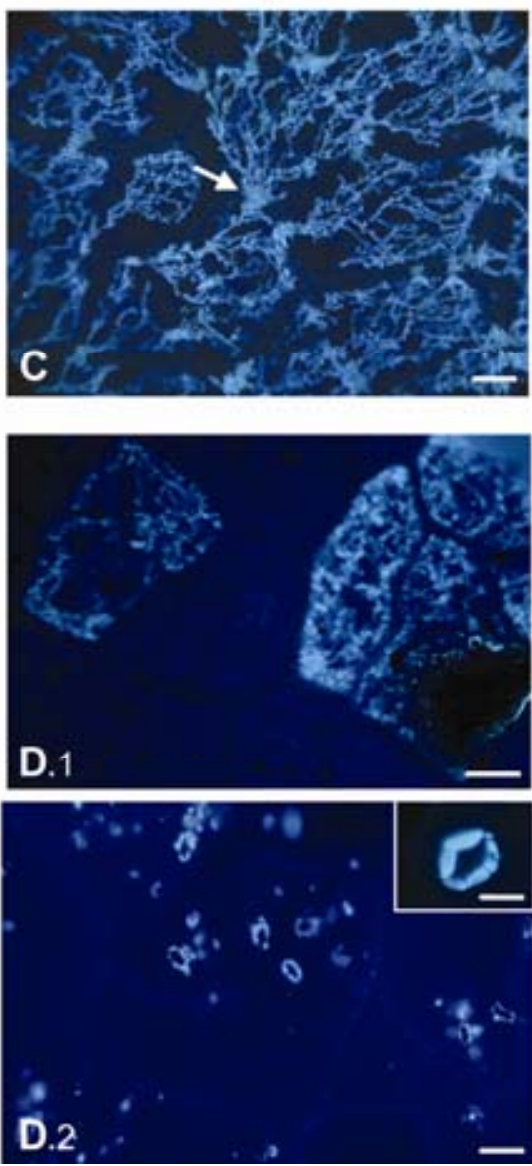

7 dpi (sporulation)
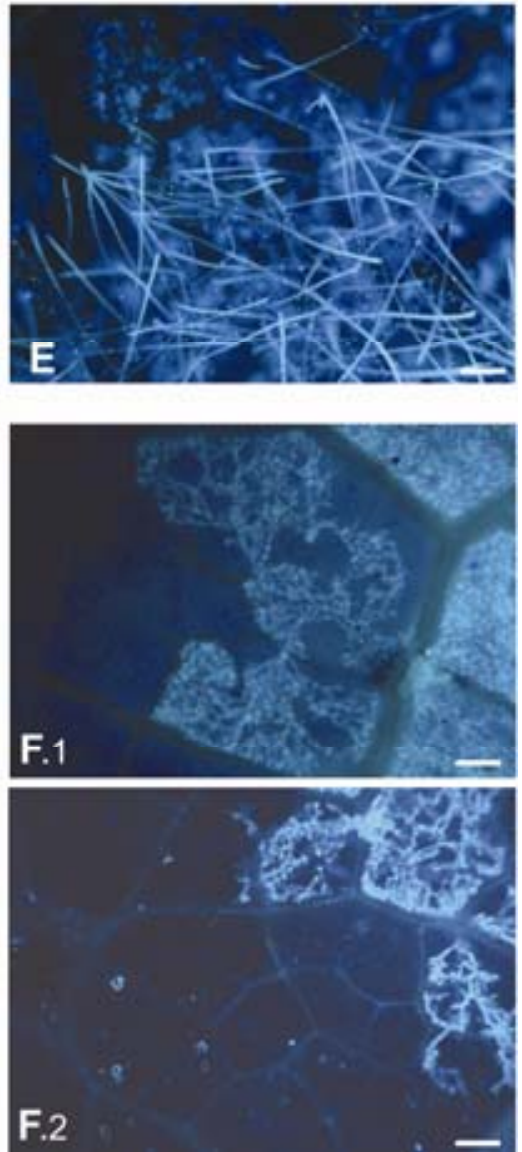

Fig. 2. Incidence of PS3 treatment on leaf tissue invasion by Plasmopara viticola. Pathogen colonization was monitored by UV epifluorescence after staining with aniline blue at different times postinoculation. All observations were made at the lower leaf surface. In surfactant control samples, the pathogen developed $\mathbf{A}$, intracellular, ramified hyphae at 3 days postinoculation (dpi), then $\mathbf{C}$, fan-shaped multibranched hyphae at 5 dpi (arrow) and E, sporangiophores at 7 dpi. B.1 and D.1, In PS3-treated samples, intercellular, ramified hyphae were observed at 3 to 5 dpi but colonization by the pathogen was reduced: B.2 and D.1, misshapen hyphae were localized in areas appearing as necrotic zones at 3 and 5 dpi. D.2, Detailed in insert, and F.2, stomata guard cells strongly fluoresced in noncolonized zones at 5 to 7 dpi, suggesting a callose deposition; F.1 and F.2, no sporulating structures were observed at 7 dpi. Bar $=40 \mu \mathrm{m}$, except D. 2 insert $=20 \mu \mathrm{m}$.
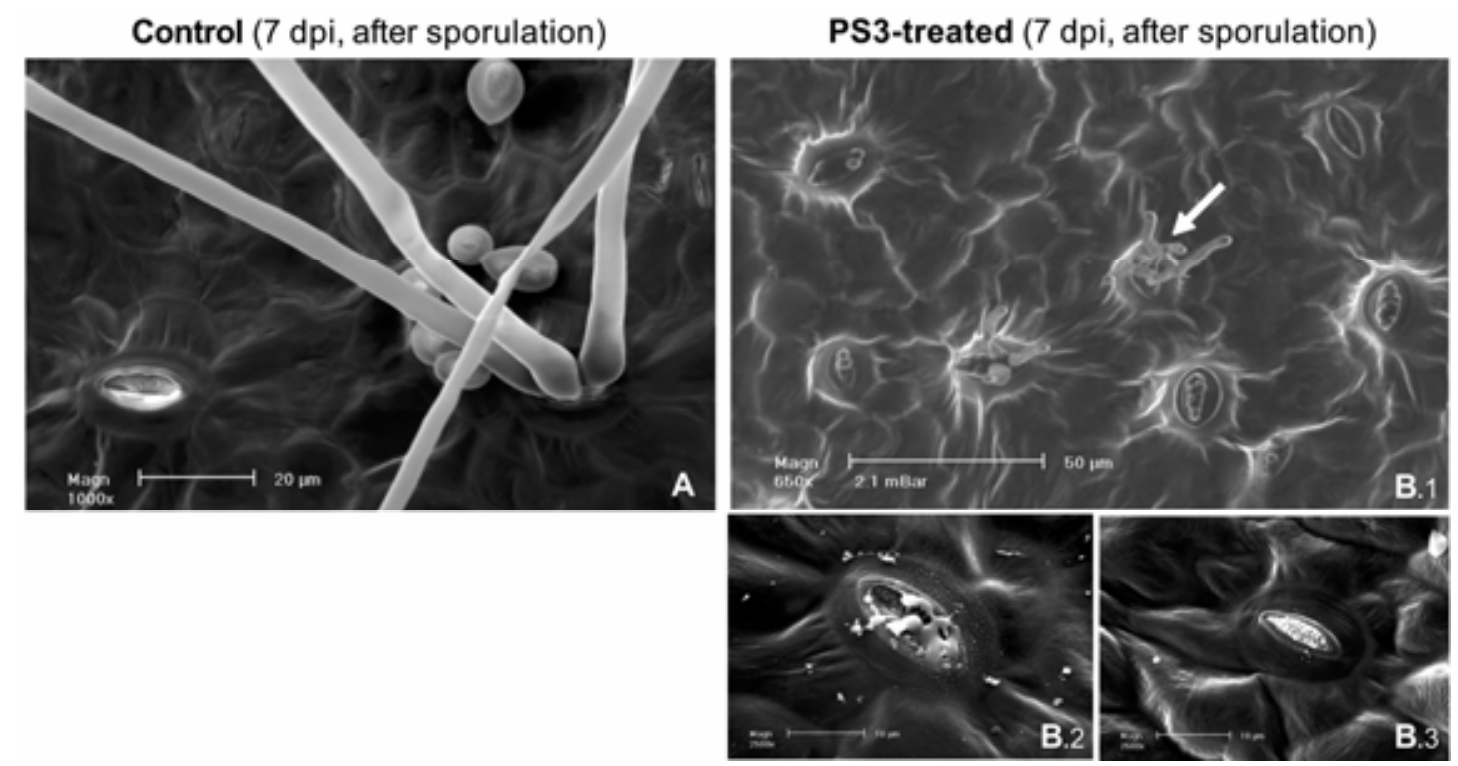

Fig. 3. Altered sporulation of the pathogen and plugging of stomata during the PS3-IR. Pictures corresponded to scanning electron micrographs of the lower leaf surface treated or not by PS3 and inoculated or not by Plasmopara viticola. All observations were made 7 days postinoculation (dpi) at the sporulation stage. A, Control samples in which sporangiophores emerged from stomata. B, PS3-treated samples; B.1, misshapen sporangiophores developed in infected zones and bore no sporangia (arrow); B.2 and B.3, in adjacent noninfected zones, secreted material was present in or over stomata. Bar: $\mathrm{A}=20 \mu \mathrm{m}, \mathrm{B} 1=50$ $\mu \mathrm{m}$, and B2-B3 = $10 \mu \mathrm{m}$. 
Uninoculated by $P$. viticola
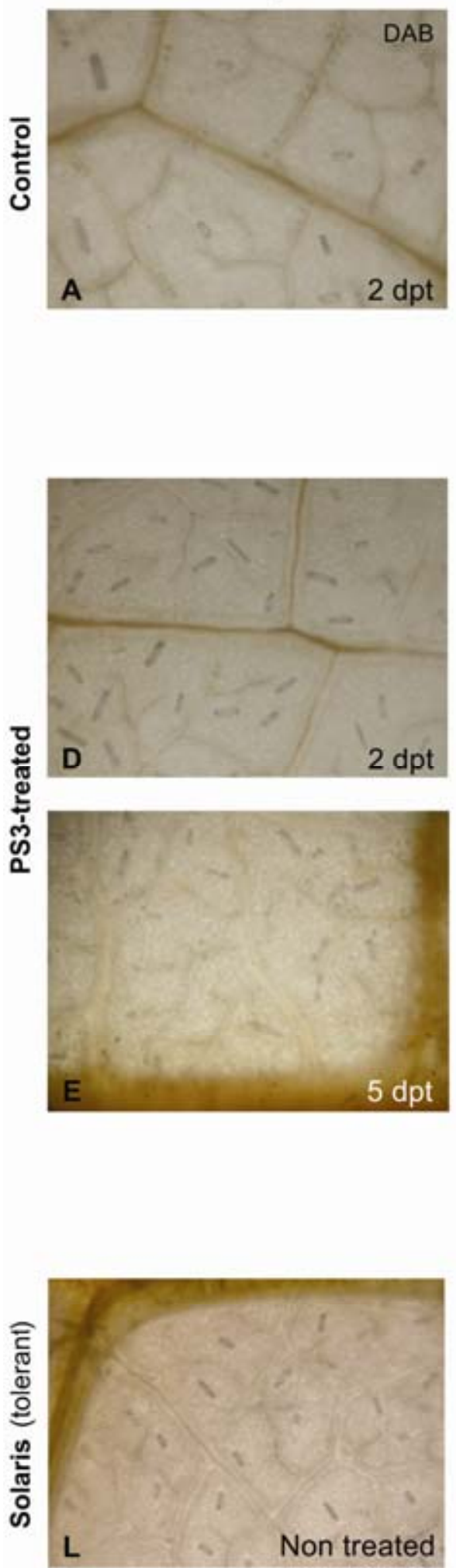

inoculated by $P$. viticola
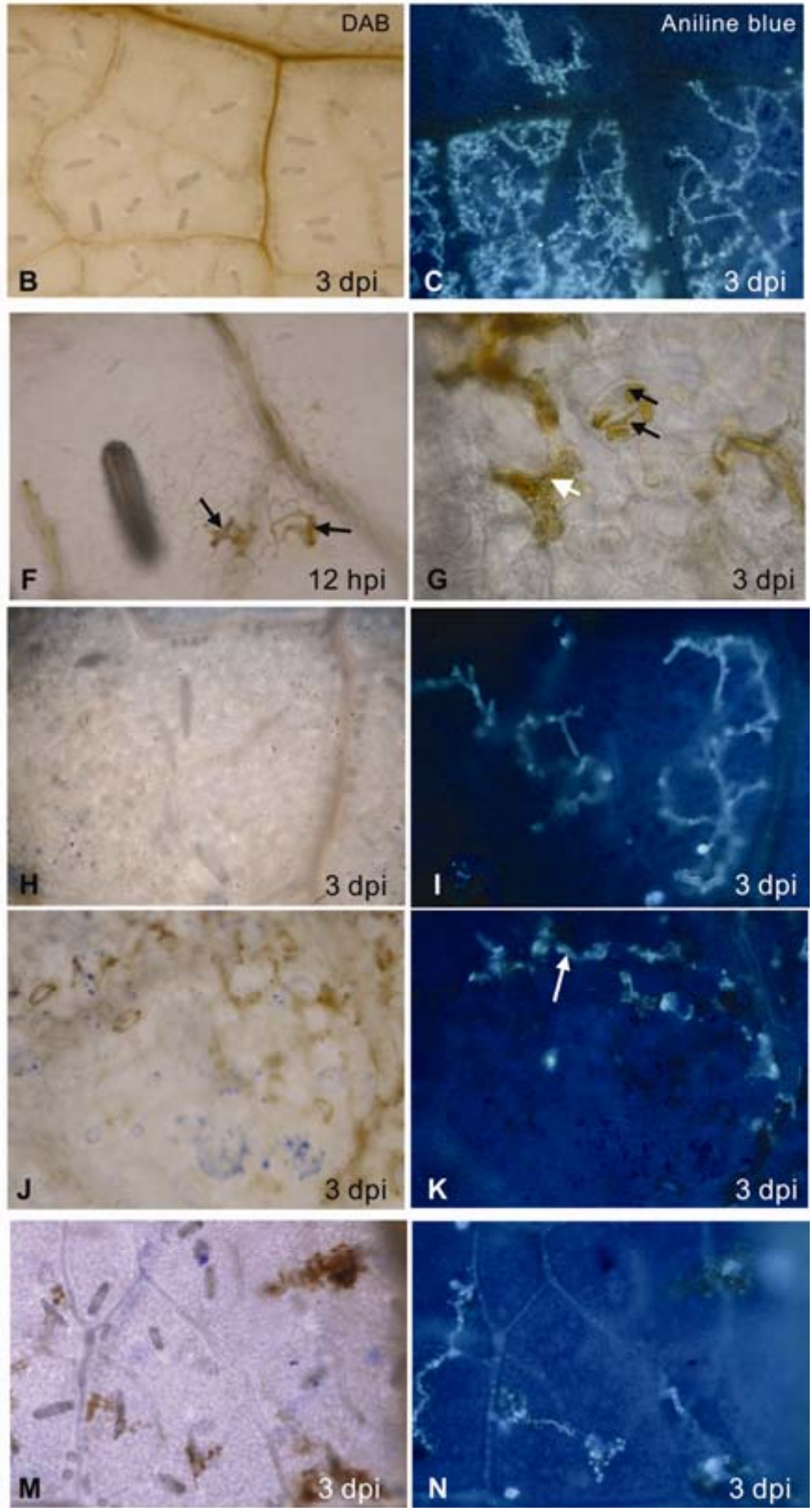

Fig. 4. Priming of $\mathrm{H}_{2} \mathrm{O}_{2}$ production in $\mathrm{PS} 3$-treated inoculated tissues. Detection of $\mathrm{H}_{2} \mathrm{O}_{2}$ produced in tissues of control susceptible plants (cv. Marselan) by A and $\mathbf{B}, 3,3$-diaminobenzidine DAB staining, $\mathbf{D}$ through $\mathbf{H}$ and $\mathbf{J}$, PS3-treated leaves, or $\mathbf{L}$ and $\mathbf{M}$, tolerant plants. A, D, E, and $\mathbf{L}$, Noninoculated or $\mathbf{B}, \mathbf{F}$ through $\mathbf{H}, \mathbf{J}$, and $\mathbf{M}$, inoculated by Plasmopara viticola. $\mathbf{C}, \mathbf{I}, \mathbf{K}$, and $\mathbf{N}$, The pathogen was monitored in the corresponding area by UV epifluorescence after staining with aniline blue. No production of $\mathrm{H}_{2} \mathrm{O}_{2}$ was detected in $\mathbf{A}$, noninoculated control or $\mathbf{D}$ and $\mathbf{E}$, PS3-treated leaves of susceptible cultivar, $\mathbf{L}$, in tolerant cultivar, or $\mathbf{B}$, in inoculated control samples of a susceptible plant despite $\mathbf{C}$, abundant colonization by the pathogen. In planta production of $\mathrm{H}_{2} \mathrm{O}_{2}$ was detected in F, PS3-treated plants of the susceptible cultivar as soon as $12 \mathrm{~h}$ postinoculation by P. viticola in a number of guard cells (arrow). G, At 3 days postinoculation, production and accumulation of $\mathrm{H}_{2} \mathrm{O}_{2}$ were principally observed in guard cells (black arrows) and in spongy parenchyma cells (white arrow). H, Foliar zones of the PS3-treated susceptible cultivar in which no DAB reaction was observed corresponded to I, those well colonized by the pathogen; in contrast, $\mathbf{J}$, a DAB reaction was observed when $\mathbf{K}$, the pathogen appeared to be affected (arrow). $\mathbf{M}$ and $\mathbf{N}$, Similar observations were made in $P$. viticola-inoculated tolerant cultivar leaves. 
Microscopical investigations revealed that PS3 primes cytological changes.

Cytological studies were undertaken to investigate cell disorganization, cell wall deposition, or accumulation of phenolic compounds, such events being described frequently in incom- patible interactions. Semithin sections were stained with toluidine blue, a polychromatic dye which can penetrate the resin, to reveal and distinguish host and pathogen structures. Light microscopy then was completed by electron microscopic investigations to precise cellular alterations.
Control
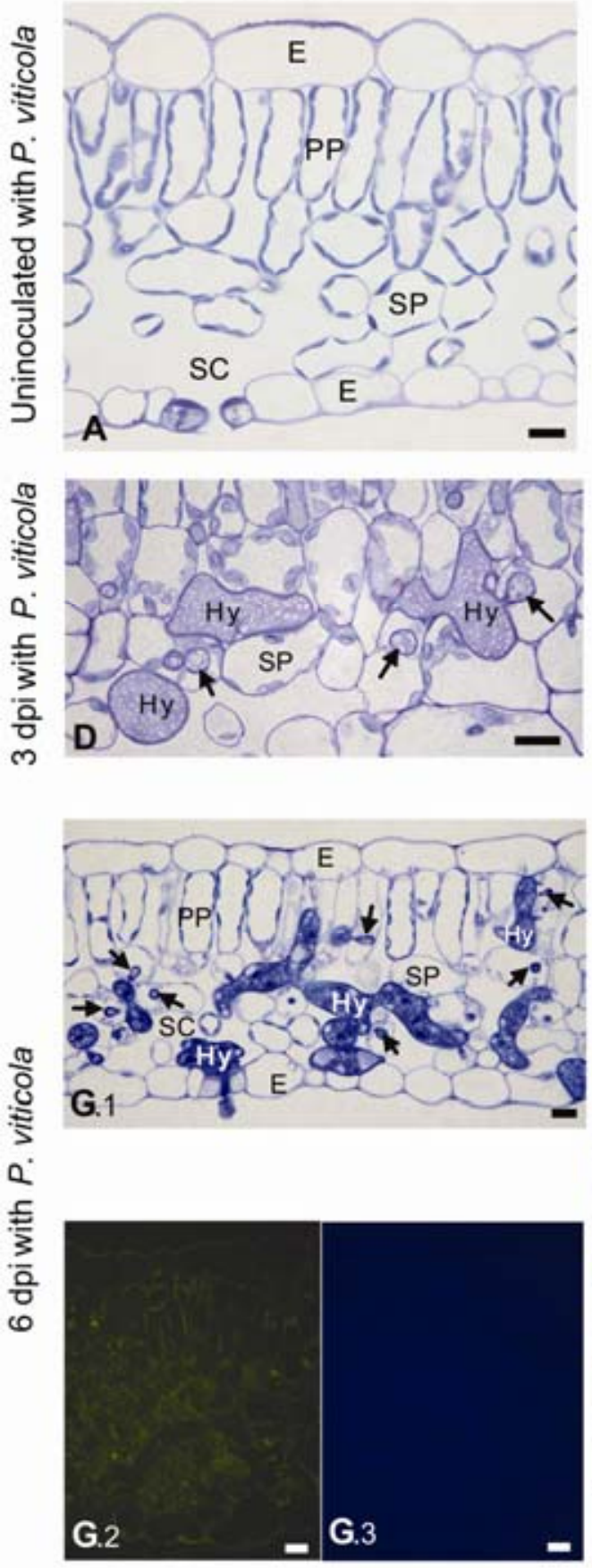

PS3-treated
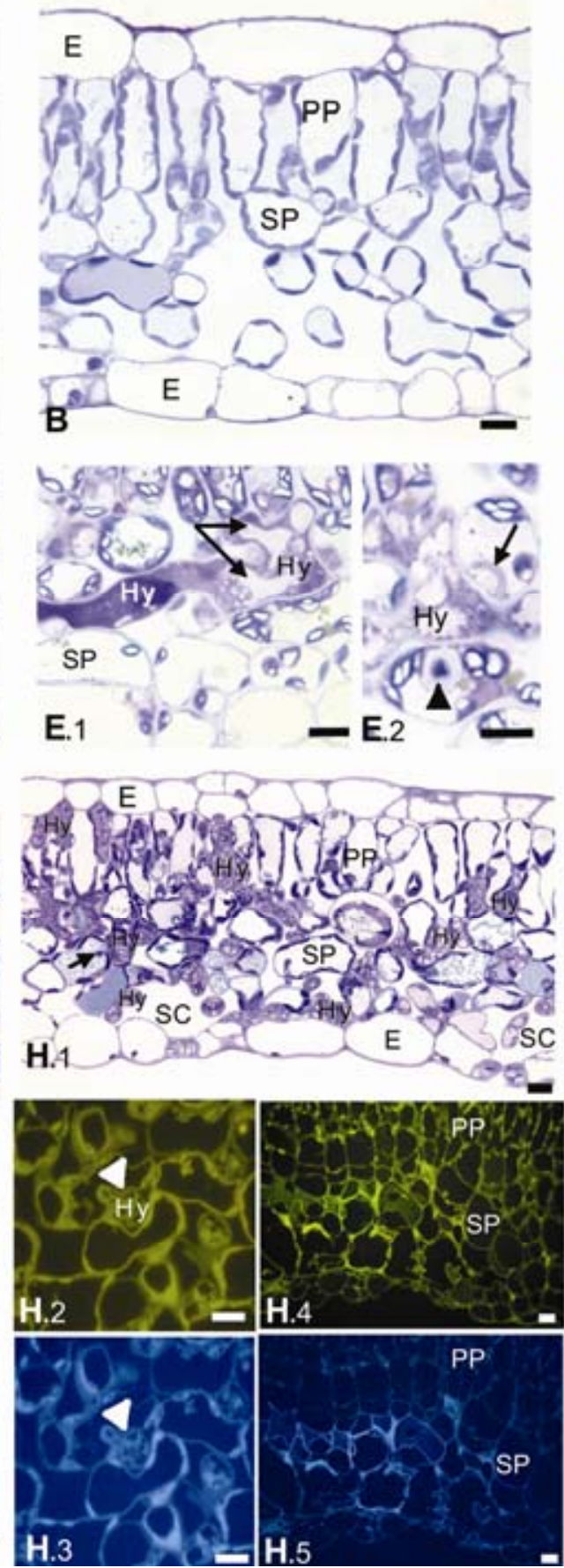

Solaris (tolerant)
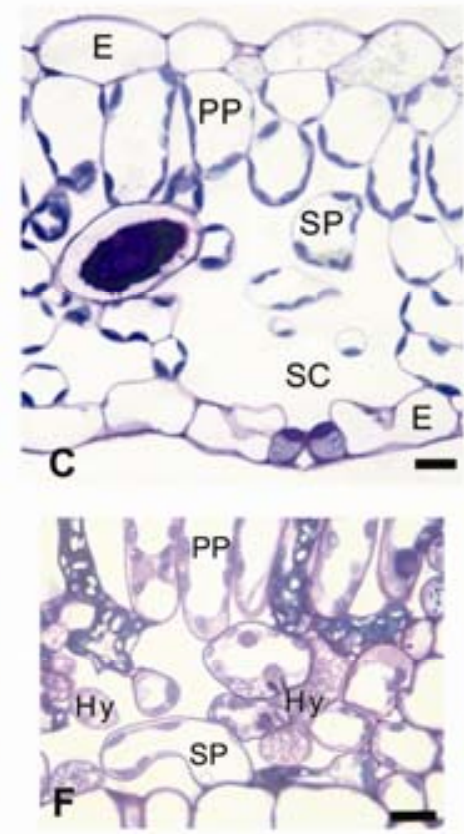

Fig. 5. Cytological study of pathogen colonization and host defenses expressed in PS3-IR (light micrographs). Pictures represent A through F, G.1, H.1, and I.1, transverse sections stained by toluidine blue or observed in epifluorescence under G.2, H.2, H.4, and I.2, blue or G.3, H.3, H.5, and I.3, UV light. Only slight modifications were detected in B, noninoculated PS3-treated tissues. E, In contrast, clear plant defense reactions were observed in inoculated PS3treated samples as soon as 3 days postinoculation (dpi). E.1, The pathogen had heterogeneous cell contents with enlarged vacuoles (arrows), and E.2, haustoria appeared collapsed (arrow) or enclosed in weakly staining plant material, possibly containing a callose-like substance (arrow head). H, Host reactions were more obvious at 6 dpi because many leaf cells had blue-stained vacuolar contents, especially H.1, those in contact with the pathogen (arrow), and H.2 through H.5, a strong autofluorescence was detected in these tissues under blue and UV light. I.1, In Solaris (tolerant), the pathogen was strongly restricted in certain areas (arrow head) characterized by numerous necrotic cells (arrows) and blue-stained vacuoles in palisadic parenchyma cells. Infected zones strongly fluoresced under I.2, blue or I.3, UV light, suggesting occurrence of phenolic compounds. E: epidermis, Hy: intercellular hyphae, PP: palisadic parenchyma cell, SC: substomatal cavity, SP: spongy parenchyma cell. Bar $=10 \mu \mathrm{m}$. 

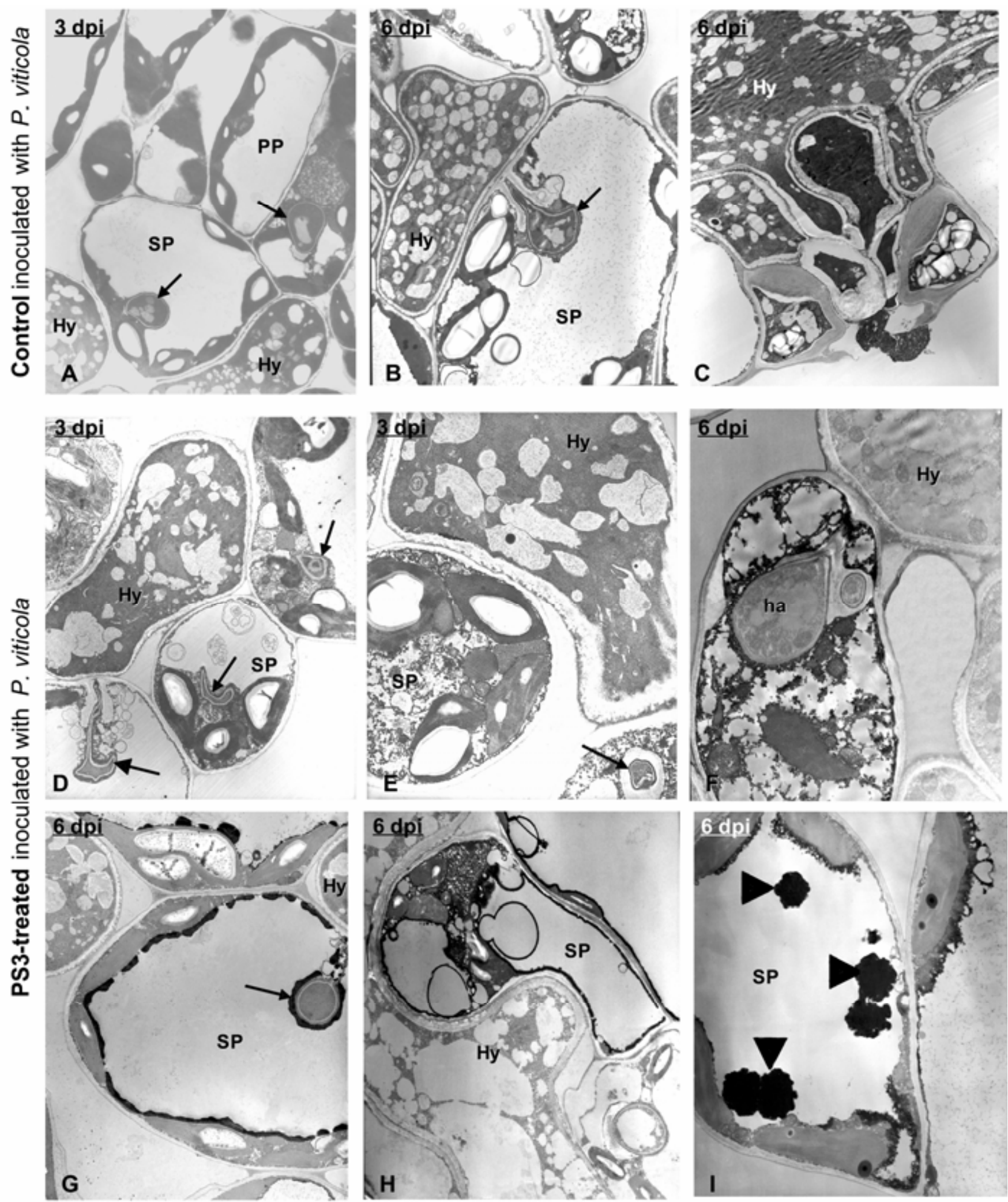

Fig. 6. Cytological study of pathogen colonization and host defenses expressed in PS3-IR (transmission electron micrographs). Pictures represent ultrathin transverse sections of $\mathbf{A}$ through $\mathbf{C}$, Plasmopara viticola-inoculated control or $\mathbf{D}$ through I, PS3-treated P. viticola-inoculated leaf segments of susceptible cultivar. A through $\mathbf{C}$, The pathogen colonized tissues of control plants intensely, as soon as 3 days postinoculation (dpi). A and $\mathbf{B}$, Well-structured haustoria were observed in parenchyma cells (arrows) and, $\mathbf{C}$, at 6 dpi, the substomatal cavity was filled with hyphae. No host defense reaction was detected at these stages. D through I, In PS3-treated leaves, clear differences appeared 3 dpi and $P$. viticola mycelium had severe ultrastructural alterations. D and E, Intercellular hyphae presented heterogeneous cell contents with enlarged vacuoles and most of the haustoria $\mathbf{D}$, appeared collapsed (arrows), with an irregular shape, or $\mathbf{E}$, enclosed in callose-like plant material (arrow). F through I, Host defense reactions were particularly obvious 6 dpi. F, Host cytoplasm appeared disorganized in some infected cells, and $\mathbf{G}$, electron-dense deposits lined host tonoplast and surrounded haustoria (arrow); $\mathbf{H}$, host cells in contact with the pathogen were highly vacuolized and I, electron-dense deposits were observed in many parenchyma cells (arrows heads); ha: haustorium, Hy: intercellular hyphae, PP: palisadic parenchyma cell, SP: spongy parenchyma cell. 
Semithin sections of uninoculated control and PS3-treated leaves revealed only slight differences 8 days posttreatment (Fig. 5A and B). In PS3-treated samples, small dark toluidine-stained patches were observed in cells and a number of plant vacuoles harbored a blue color (Fig. 5B).

In untreated inoculated samples, at $3 \mathrm{dpi}$, hyphae were clearly visible in intercellular spaces with a homogenous cell content and formed pear-shaped haustoria in host cells (Fig. 5D, arrows). Most of the leaf tissues became colonized and no obvious host reactions were observed (Fig. 6A and 6B). At 6 dpi, the pathogen had reached substomatal cavities (Figs. 5G.1 and $6 \mathrm{C}$ ). The picture was very different at 3 and 6 dpi in PS3treated inoculated samples. Hyphal growth was reduced and intercellular hyphae had heterogenous cell contents which were either darkly stained by toluidine blue or very highly vacuolated (Fig. 5E.1). Some haustoria appeared collapsed or encased in lightly staining plant material (Fig. 5E.2, arrow head) and deposits were present in the vacuoles of many plant parenchymal cells. Alteration of hyphal and haustorial contents was confirmed by transmission electron microscopy observations (Fig. 6D and E). Spongy parenchyma cells of PS3treated samples had granular vacuolar contents, particularly those penetrated by the pathogen (Fig. 5H.1, arrow). Host cell walls and hyphae strongly fluoresced under blue and UV light in PS3-treated samples (Fig. 5H.2 to H.5), whereas there was only a faint fluorescence in infected control leaves (Fig. 5G.2 and G.3) or in uninoculated PS3-treated samples (not shown). In infected PS3-treated leaves, some host cells presented cytoplasmic disorganization evoking $\mathrm{HR}$ cell death (Fig. 6F and $\mathrm{H}$ ) whereas, in other cells, electron-dense deposits coated the inner face of the tonoplast (Fig. 6G) or accumulated in the vacuole (Fig. 6I) and surrounded haustoria which had penetrated the cell lumen (Fig. 6G, arrow).

These observations are similar to those made on untreated but inoculated leaves of the tolerant cv. Solaris (Fig. 5F and I). However, tissue and cell reactions induced in response to $P$. viticola inoculation in this tolerant grapevine cultivar were more intense than in the PS3-treated susceptible Marselan plants. Numerous spongy parenchyma cells were necrotic in infected zones (Fig. 5I.1, arrows) and pathogen colonization was greatly restricted (Fig. 5I.1, arrow head). Vacuoles of palisade parenchyma cells stained green-gray with toluidine blue (Fig. 5I.1) and cell contents strongly fluoresced under blue and UV light (Fig. 5I.2 and I.3). These observations at the cellular level showed that PS3 treatment was associated with HR-like cell death and deposition of phenolics only after challenge with $P$. viticola. Moreover, these reactions were similar to those observed in the tolerant inoculated cv. Solaris, indicating that they are involved in grapevine resistance against $P$. viticola.

\section{Upregulation of defense-related gene expression in PS3-treated uninoculated susceptible plants.}

The expression of six genes known to be involved in defense was analyzed using real-time quantitative polymerase chain reaction (qPCR) and specific primers (Table 1). These genes encode phenylalanine ammonia lyase $(P A L)$, a key enzyme of the phenylpropanoid pathway; stilbene synthase (STS), downstream of PAL and responsible for the synthesis of resveratrol; 9-lipoxygenase $(L O X)$, an enzyme of the octadecanoid pathway; glutathione- $S$-transferase $(G S T)$, an enzyme with detoxifying properties; a protease inhibitor $(P I N)$ of the PR-6 family; and a PR-3, that is, a basic class I chitinase (CHITIb) (Fig. 7). In control plants treated with surfactant alone, a very weak accumulation of transcripts was observed 24 and 48 h posttreatment compared with nontreated plants, indicating that this component slightly modulated gene transcript levels (Fig. 7). In contrast, all the genes were upregulated in PS3-treated plants. Maximum levels of transcripts were observed at $24 \mathrm{~h}$ posttreatment except for PIN gene. At this moment, the largest ratios of induction factors between PS3- and surfactant-treated plants were obtained for GST, STS, and PIN genes $(\times 31, \times 19$, and $\times 15$, respectively).

\section{PS3 potentiates the induction of defense-related genes in susceptible plants infected with $P$. viticola.}

The relative expression of defense-related genes was compared ( $1 \mathrm{dpi}$ ) between $P$. viticola-inoculated or mock-inoculated plants after pretreatment with water, surfactant, or PS3 (Fig. 8). Induction of gene expression was generally weak in $P$. viticola-inoculated plants pretreated with water or surfactant

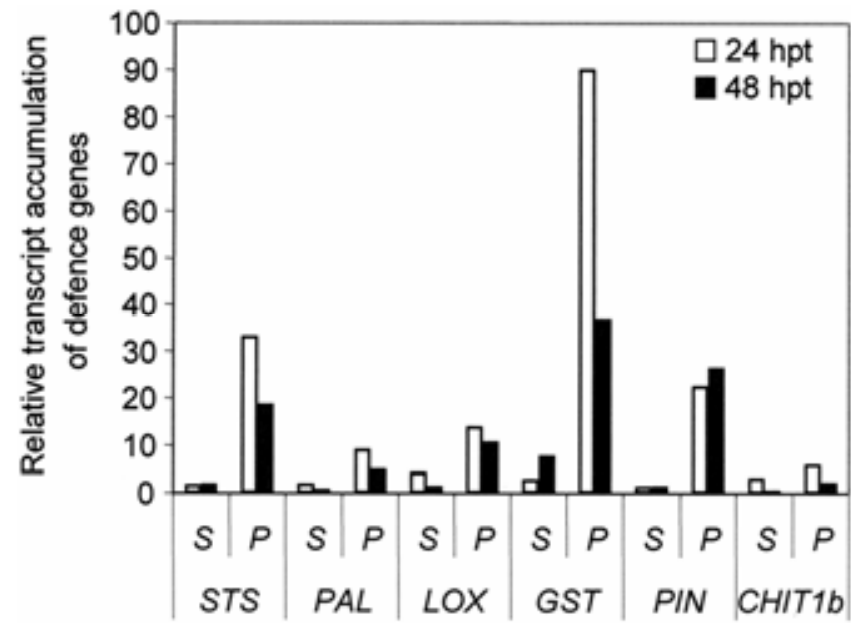

Fig. 7. Defense-related gene expression in susceptible cultivar leaves after treatment with PS3. The transcript accumulation of genes encoding stilbene synthase $(S T S)$, phenylalanine ammonia lyase $(P A L)$, 9-lipoxygenase $(L O X)$, glutathione- $S$-transferase $(G S T)$, protease inhibitor $(P I N)$, and basic class I chitinase $(C H I T 1 b)$ was determined by real-time reverse-transcription polymerase chain reaction in samples treated by $0.1 \%$ surfactant alone $(\mathrm{S})$ or by PS3 at $5 \mathrm{~g}^{\text {.liter }}{ }^{-1}$ in the surfactant $(\mathrm{P})$, and harvested $24 \mathrm{~h}$ posttreatment (hpt) (white bars) or $48 \mathrm{hpt}$ (black bars). Results are expressed as the fold increase in transcript level compared with the control (water-treated) leaves and are means of duplicate data from one representative experiment among two independent repetitions. Standard deviations are too small to represented.

Table 1. Primers used for amplification of defense-related gene cDNAs

\begin{tabular}{|c|c|c|c|}
\hline Name & Identification $^{\mathbf{a}}$ & Forward primer $\left(5^{\prime}\right.$ to $\left.3^{\prime}\right)$ & Reverse primier $\left(5^{\prime}\right.$ to $\left.3^{\prime}\right)$ \\
\hline EF1 & EC959059 & GAACTGGGTGCTTGATAGGC & AACCAAAATATCCGGAGTAAAAGA \\
\hline STS & X76892 & AGGAAGCAGCATTGAAGGCTC & TGCACCAGGCATTTCTACACC \\
\hline$P A L$ & X75967 & TCCTCCCGGAAAACAGCTG & TCСТССААATGCСТСАAАTCA \\
\hline$L O X$ & AY159556 & СССTTCTTGGCATCTCCCTTA & TGTTGTGTCCAGGGTCCATTC \\
\hline$G S T$ & AY 156048 & TGCATGGAGGAGGAGTTCGT & CAAGGCTATATCCCCATTTTCTTC \\
\hline$P I N$ & AY 156047 & AGTTCAGGGAGAGGTTGCTG & CGTCGACCCAAACACGGACCCTAGTGC \\
\hline CHIT1b & Z54234 & CCCAAGCCTTCCTGCCATA & TGTGATAACACCAAAACCGGG \\
\hline
\end{tabular}

a NCBI accession number or TC TIGR number. 
and in mock-inoculated plants pretreated with the surfactant alone. These results indicate that fungal infection alone caused only a slight modulation of gene expression and that pretreatment by the surfactant before infection did not potentiate a

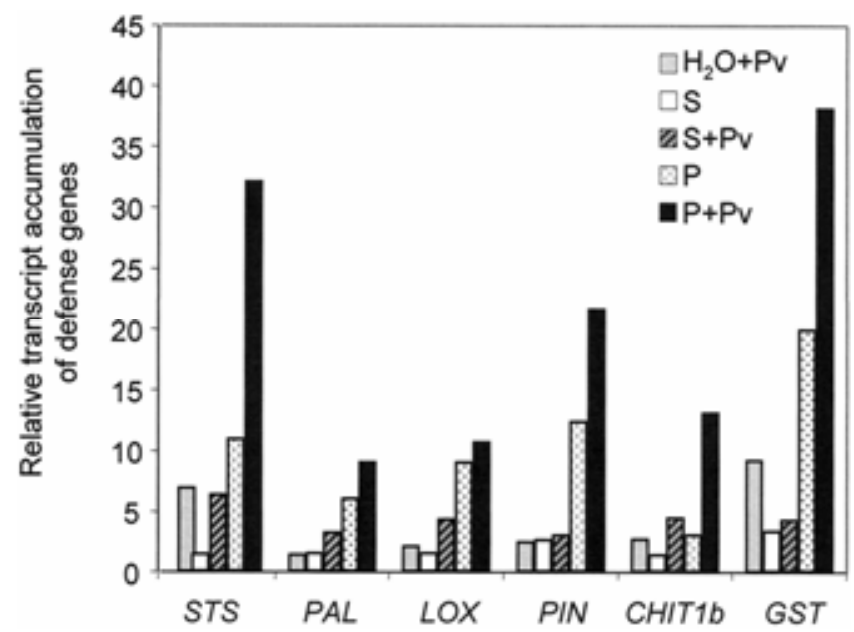

Fig. 8. Enhancement of defense-related gene expression in PS3-treated plants in response to Plasmopara viticola inoculation. Plants were sprayed with water $\left(\mathrm{H}_{2} \mathrm{O}\right), 0.1 \%$ surfactant $(\mathrm{S})$, or PS3 at 5 g.liter $^{-1}$ in the surfactant $(\mathrm{P}) 2$ days before inoculation with $P$. viticola $(+P v)$ or mock inoculation. Transcript accumulation of genes encoding stilbene synthase (STS), phenylalanine ammonia lyase $(P A L)$, 9-lipoxygenase $(L O X)$, glutathione$S$-transferase $(G S T)$, protease inhibitor $(P I N)$, and basic class I chitinase $(C H I T 1 b)$ was determined by real-time reverse-transcription polymerase chain reaction $24 \mathrm{~h}$ postinoculation with $P$. viticola or $24 \mathrm{~h}$ after mock inoculation. Results are expressed as the fold increase in transcript levels as compared to non-treated leaves and are from one representative experiment among two independent repetitions. plant response in terms of defense gene activation. Except for $C H I T 1 b$, a stronger gene response was observed in mockinoculated plants pretreated with PS3; however, the strongest gene induction occurred in $P$. viticola-inoculated plants pretreated with PS3. For $P A L$ and $L O X$, this induction was quite similar to the sum of the expression of the separate treatments; however, for STS, GST, PIN, and CHITlb, it was much higher than the sum of the expression of the separate treatments. Taken together, these results suggested that PS3 potentiated the induction of the defense-related genes under study in response to a subsequent infection by $P$. viticola.

\section{Callose and JA-dependent defenses seem to be involved} in PS3-induced resistance against $P$. viticola.

The role of callose, the phenylpropanoid pathway, and JA in PS3-IR was checked using specific inhibitors of enzymes involved in these pathways: 2-deoxy-D-glucose (DDG) as an inhibitor of callose synthesis, 2-aminoindan-2-phosphonic acid (AIP) as an inhibitor of the PAL, and 5, 8, 11, 14-eicosatetraynoic acid (ETYA) as an inhibitor of the LOX.

Leaf disks were treated with the inhibitor prior to treatment with PS3, then inoculated with $P$. viticola, and the index of sporulation per leaf disk was determined at $5 \mathrm{dpi}$.

In the susceptible cv. Marselan, pathogen growth was not significantly different between control plants treated with surfactant alone or treated with AIP, DDG, or ETYA (Fig. 9). This demonstrated that these inhibitors had no effect by themselves on grapevine resistance and on $P$. viticola. In contrast, in PS3treated disks, the pathogen sporulation was nearly abolished. The index of sporulation significantly increased with the application of DDG and ETYA but remained lower than in control samples untreated with PS3, whereas AIP did not reduce the protective effect.

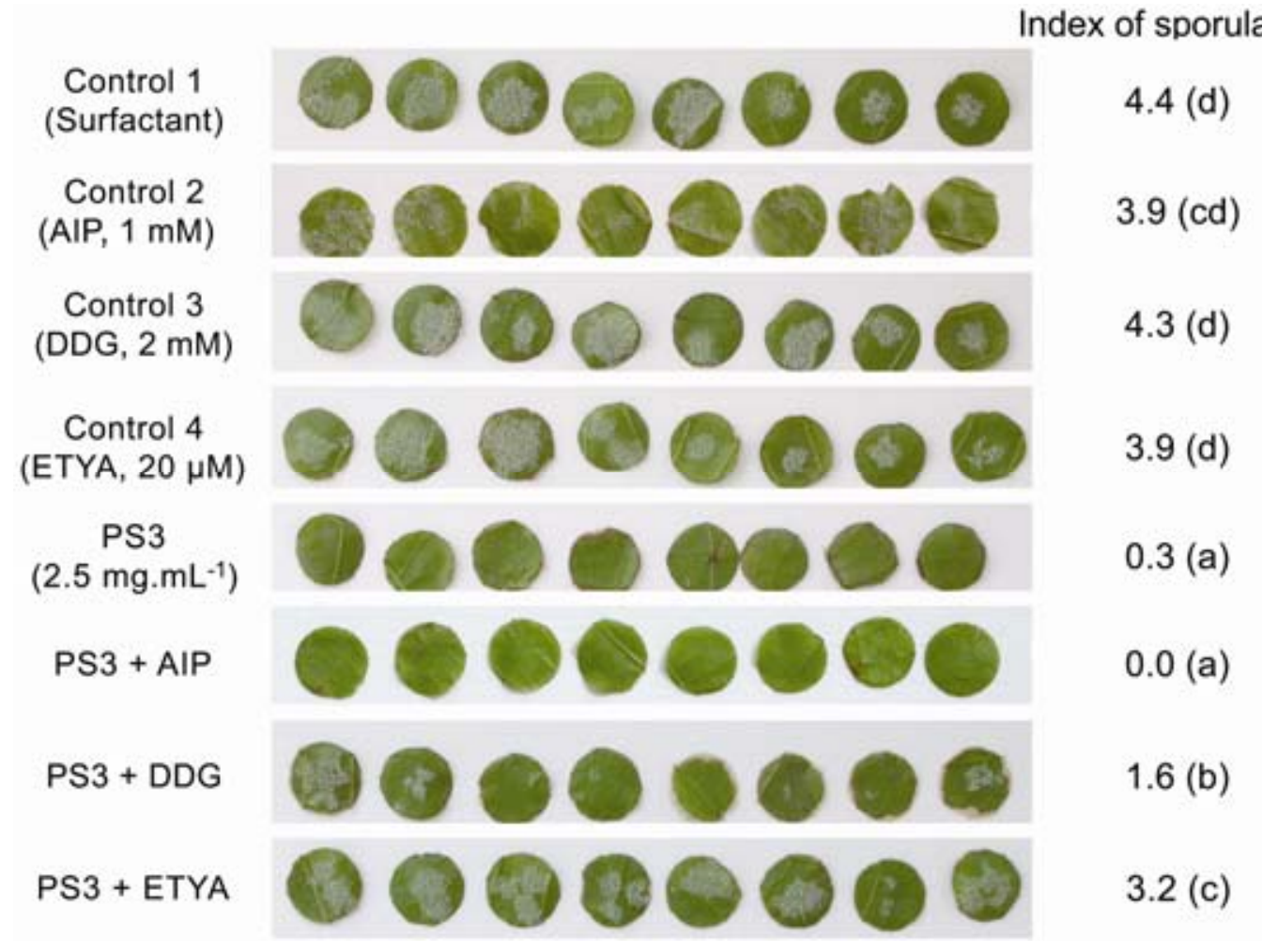

Fig. 9. Effect of specific inhibitors on the PS3-IR against Plasmopara viticola. Foliar disks were treated with inhibitor solutions (2-aminoindan-2-phosphonic acid [AIP], inhibitor of phenylalanine ammonia lyase; 2-deoxy-D-glucose [DDG], inhibitor of callose synthase; and 5, 8, 11, 14-eicosatetraynoic acid [ETYA], inhibitor of 9-lipoxygenase) prior to the PS3 treatment. Pictures were from a representative experiment. The index of sporulation was scored at 5 days postinoculation on a scale of 0 to 5 , where $0=$ no visible sporulation, $1=1$ to $10 \%, 2=10$ to $25 \%, 3=25$ to $50 \%, 4=50$ to $75 \%$, and $5=75$ to $100 \%$ of the disk area covered. Values represent the mean index from two independent experiments. Values of index followed by the same letter are not significantly different $(P<0.05)$. 
Microscopical observations (not shown) allowed us to verify that DDG treatment prior to PS3 suppressed callose deposits and increased growth of the pathogen compared with PS3treated samples. With ETYA, the colonization and the sporulation in the PS3-treated disks were even higher than in the case of DDG.

At the macroscopic level, these inhibitors failed to suppress natural resistance in Solaris, though cytological observations revealed that inhibitors slightly increased the infection (AIP) and the number of sporangiophores (DDG and ETYA).

Taken together, these results suggested that callose deposition and the JA pathway contribute to PS3-IR but that the phenylpropanoid pathway appeared to be not crucial.

\section{DISCUSSION}

PS3 foliar application reduced $P$. viticola infection in the susceptible cv. Marselan under glasshouse conditions by severely limiting colonization of leaf tissues and blocking sporulation of the pathogen. Given that this compound is not directly toxic to the oomycete, and considering the cytological and molecular data presented here, it can be inferred that its efficacy relied on the priming of grapevine defense reactions.

$\mathrm{H}_{2} \mathrm{O}_{2}$ is considered to be a signaling molecule in plant defense, produced following successful pathogen recognition (Levine et al. 1994). It is involved in defense genes activation, cross-linking occurring in cell wall reinforcement, systemic acquired resistance establishment, and HR (Torres et al. 2006). $\mathrm{H}_{2} \mathrm{O}_{2}$ production is one of the earliest detectable cytological responses in leaves of PS3-treated inoculated plants. DAB reaction was observed as soon as 12 hpi in P. viticola-challenged PS3-treated grapevine, a timing consistent with that of incompatible interactions where $\mathrm{H}_{2} \mathrm{O}_{2}$ is detected within 6 to $24 \mathrm{~h}$ following inoculation (Mellersh et al. 2002; Thordal-Christensen et al. 1997) or in challenged tolerant Solaris plants (our data). At this early time, no haustorium has been formed yet; therefore, one can assume that, in treated grapevine tissues, cells, including guard cells, are able to detect the simple contact of the growing germ tube or encysted zoospores or compounds released by these structures. The subsequent $\mathrm{H}_{2} \mathrm{O}_{2}$ production detected up to 3 dpi in leaf cells may be related to the extension of hyphae in host tissue and haustorial formation. The observed colocalization of hyphae alteration and $\mathrm{H}_{2} \mathrm{O}_{2}$ production suggests a direct antimicrobial effect of $\mathrm{H}_{2} \mathrm{O}_{2}$ on P. viticola or an indirect effect through the localized HR-like host cell death described below.

Tissues of control samples of cv. Marselan were heavily colonized by $P$. viticola and no defense reaction was observed, as formerly described by Langcake and Lovell (1980) for downy mildew-susceptible Vitis spp. In contrast, PS3 treatment is unequivocally associated with cytological changes, observed as soon as $3 \mathrm{dpi}$ in both host and pathogen tissues. Collapsing haustoria occurred concomitantly with alterations in host cells in contact with the pathogen. In line with DAB results, this picture evokes HR cell death, akin to what was observed during incompatible interactions ( $\mathrm{Hu}$ et al. 2003; Soylu et al. 2004). Thus, in contrast to what is commonly believed, an oligosaccharidic elicitor can induce localized cell death, provided the plant has been challenged by an appropriate pathogen.

In later observations in PS3-treated tissue (6 dpi), haustoria surrounded by electron-dense material often were found. The latter, as well as electron-dense deposits within the host cell vacuoles, probably corresponded to phenolic compounds because they autofluoresced (Carver et al. 1994). These observations were in concordance with potentiated induction of $P A L$ and STS genes in treated, inoculated plants. Therefore, it appears likely that phenolic compounds accumulate as part of the
PS3-related defense response induced by $P$. viticola in $\mathrm{cv}$. Marselan, as was suggested in the case of induced resistance by chitosan in tomato against Fusarium spp. (Benhamou et al. 1994). Inhibition of $P$. viticola sporulation, which is a marked trait of PS3 effect, is certainly a consequence of the induced defense reactions which may hamper nutrient uptake by the pathogen's haustoria.

We assume that blue fluorescent secretions in stomata of PS3-treated cv. Marselan, in zones adjacent to those infected by $P$. viticola, correspond to induced callose deposition (Gindro et al. 2003). Such a reaction also was described in the case of $\beta$-aminobutyric acid (BABA)-induced resistance in grapevine against $P$. viticola (Hamiduzzaman et al. 2005). Hence, PS3 and BABA share some common effects.

The similarity of $P$. viticola-induced $\mathrm{H}_{2} \mathrm{O}_{2}$ production and cytological changes occurring in treated plants to those observed in the tolerant grapevine cv. Solaris reflect, to a certain extent, a change from a compatible interaction to an incompatible one after PS3 treatment in cv. Marselan.

A striking result is that no significant $\mathrm{H}_{2} \mathrm{O}_{2}$ production or cytological modifications were observed in either the $P$. viticolainfected control or PS3-treated uninfected plants. This indicates that pathogen inoculation is required for the observed PS3induced defense reactions to be activated. The picture is not so clear-cut in terms of defense gene expression because gene activation, though weak, was observed in pathogen-infected control leaves, indicating that the plant had perceived the infection, and also in PS3-treated noninfected plants, illustrating an elicitor effect of PS3. However, after PS3 treatment, expression of five of six genes clearly is enhanced in the presence of the pathogen compared with upregulation in the other conditions. Taken together, the present cytological and molecular data lead us to conclude that PS3 potentiates an enhanced defense reaction in susceptible grapevine. This phenomenon, also termed priming, consists of a physiological condition in which plant defense reactions are activated more intensely and more rapidly in response to biotic or abiotic stress (Conrath et al. 2006). The mechanisms underlying this phenomenon are still poorly understood. Priming previously has been described in grapevine in the case of BABA-induced resistance against $P$. viticola (Hamiduzzaman et al. 2005). BABA was shown to prime marker genes of salicylic acid (SA) and JA pathways, as well as callose and lignin deposition around infection sites. However, to our knowledge, it is the first time that an oligosaccharide has been found to prime defense reactions. Ménard and associates (2004) reported that PS3 elicited various defense reactions in tobacco and strongly reduced TMV infection. Though one cannot rule out the priming of other defense pathways, these authors concluded that PS3 behaves as an elicitor in tobacco rather than a priming agent, which infers that the PS3 effect may vary according to the plant species. Interestingly and as expected, a recent study demonstrated that priming has a lower metabolic cost to the plant than that of direct elicitation of defense reactions (Van Hulten et al. 2006), which is certainly valuable in terms of crop protection.

PS3 is an inducer of SA- and ethylene-related defense pathways in tobacco and Arabidopsis (Ménard et al. 2004). In a first approach to gain insight into its mode of action in grapevine, we used different inhibitors which do not affect $P$. viticola. AIP, a specific inhibitor of PAL (Zon and Amrhein 1992), did not reduce PS3 protection against $P$. viticola, indicating that the phenylpropanoid pathway is not critical for PS3-IR against this pathogen. This also suggests that this resistance should not require SA unless it is synthesized in grape via the shikimate instead of the PAL pathway (Métraux 2002). Thus, it will be interesting to measure SA levels in PS3-treated grape in the presence or not of the PAL inhibitor AIP. Because AIP 
also blocks synthesis of phytoalexins and others phenolics, these compounds, though obviously present in the challenged cells, consequently should be nonessential for PS3-IR. This finding is not in accordance with the commonly considered role of phenolics in the plant's defense. One explanation may reside in the fact that these deposits originate from preformed pools of phenolics in the cells.

Reducing PS3 efficacy by $30 \%$ with DDG, an inhibitor of callose synthesis, indicates that callose deposition is a component of PS3-IR. Moreover, ETYA, an inhibitor of LOX, was much more potent, reducing resistance by $80 \%$, suggesting that PS3-IR principally relies on the JA pathway. This result is in agreement with the potentiated expression of the $L O X$ gene following PS3 treatment and inoculation. However, with ETYA also being an inhibitor of phospholipases A, one cannot preclude a role for fatty acids and phospholipids in PS3 signalization. It is noteworthy that similar assays and conclusions with the same inhibitors were reported by Hamiduzzanam and associates (2005) when studying BABA-IR against $P$. viticola. Thus, the mode of action of PS3 and BABA share common traits.

Taking into account that the grape genome recently has been sequenced, investigating pathways involved in PS3-induced resistance will undoubtedly be an interesting task. Moreover, its potential for priming defense against other serious grape diseases, such as powdery mildew, needs to be assessed in order to evaluate its range of activity and its value to implement induced resistance strategies in crop production systems.

\section{MATERIALS AND METHODS}

\section{Plant material.}

Two grapevine cultivars were used: $V$. vinifera L. cv. Marselan (Cabernet sauvignon $\times$ Grenache) and the hybrid Solaris, which are susceptible and tolerant, respectively, to $P$. viticola.

Grapevine plants were obtained from herbaceous cuttings placed in individual pots ( 10 by 10 by $8 \mathrm{~cm}$ ) containing a mixture of blond peat, sand, and perlite $(4: 1: 1, \mathrm{vol} / \mathrm{vol} / \mathrm{vol})$. They were grown in a glasshouse at a temperature of 24 and $18^{\circ} \mathrm{C}$ (day and night, respectively) with a photoperiod of $16 \mathrm{~h}$ of light and at a relative humidity (RH) of $70 \pm 10 \%$ until they developed six leaves. Plants were watered daily and a fertilizing solution was supplemented once a week.

\section{Elicitor preparation and application.}

PS3 was tested at different concentrations between 1.25 and $5 \mathrm{mg} / \mathrm{ml}$ prepared in $0.1 \%$ surfactant (confidential) in order to improve its penetration throughout the foliar cuticle. The test solutions were applied to both upper and lower leaf surfaces until the point of run-off using a manual sprayer. Pots were arranged in a randomized block design in the glasshouse. Except as otherwise mentioned, controls were sprayed with surfactant.

\section{Pathogen.}

A downy mildew (P. viticola) isolate, obtained from a Burgundy vineyard, was maintained on Marselan herbaceous cuttings in the glasshouse under the conditions described above. To obtain sporangia, plants presenting oily spot symptoms were placed in the dark at $100 \%$ RH overnight. Sporangia then were collected from the lower leaf side using a brush and suspended in distilled water. The concentration was adjusted to $10^{4}$ sporangia per milliliter using a Malassez hemacytometer.

\section{Inoculation and disease assessment.}

Two days after elicitor treatment, leaves of treated and control grapevine plants were inoculated by spraying a freshly prepared sporangia suspension onto the underside. Inoculated shoots were placed overnight in a humid chamber. They were replaced in the glasshouse the following morning.

After 7 to 8 days in the glasshouse, plants were placed in a humid chamber overnight to provoke pathogen sporulation. Disease intensity then was assessed by measuring the leaf area covered by sporulation. In each experiment, six grapevine plants were observed per treatment.

In order to compare values for infection levels, analysis of variance was performed with the statistical program STATGRAPHICS release 5.1 (Manugistic, Inc., Rockville, MD, U.S.A.) using the least significant difference (LSD) test to detect significant differences $(P<0.05)$ between treatments.

\section{Evaluation of a direct effect of PS3 on $P$. viticola sporangia and zoospores.}

Freshly prepared sporangia were incubated with elicitor preparation for $10 \mathrm{~min}$ and then stained for $3 \mathrm{~min}$ with a combination of 5,6 carboxyfluorescein diacetate and propidium iodide (in vitro experiment). Under blue excitation $\left(\lambda_{\text {exc }} 495\right.$ $\mathrm{nm}$, stop filter LP $510 \mathrm{~nm}$ ), live sporangia produce a green fluorescence $\left(\lambda_{\text {em }} 520 \mathrm{~nm}\right)$ whereas dead ones fluoresce red $\left(\lambda_{\mathrm{em}} 617 \mathrm{~nm}\right)$. Direct effects also were determined on leaves previously treated with elicitor preparation (adapted from Sergeeva et al. 2002). Seven days post-elicitor treatment, one drop (30 $\mu \mathrm{l})$ of sporangia suspension was placed on a leaf disk. The fluorochromes were added $10 \mathrm{~min}$ later, and observations made after $3 \mathrm{~min}$ of incubation (in planta experiment). A minimum of 100 sporangia was counted each time (three repetitions) and experiments were repeated three times independently. PS3 was tested at different concentrations between 0.1 and $5 \mathrm{mg} / \mathrm{ml}$ alone (in vitro) or prepared at $5 \mathrm{mg} / \mathrm{ml}$ in $0.05 \%$ surfactant (in planta). The direct effect of the surfactant alone also was checked in vitro.

Evaluation of toxic effect on zoospores was achieved indirectly. PS3 (5 mg/ml prepared in water) was sprayed on plants and, $4 \mathrm{~h}$ later (a time supposed to be too early for defense reactions to be active), leaf disks (diameter, $1 \mathrm{~cm}$ ) were punched out, placed in a petri dish on wet filter paper, and inoculated with one drop $(30 \mu \mathrm{l})$ of a $10^{5}$ sporangia/ml suspension. $P$. viticola development in the tissue was assessed 2 dpi after aniline blue staining (discussed below) and 6 dpi by observing sporulation on disks.

\section{Localization of $\mathrm{H}_{2} \mathrm{O}_{2}$ in treated leaves.}

Leaves from plants previously treated by spraying PS3 (5 $\mathrm{mg} / \mathrm{ml}$ in $0.1 \%$ surfactant), $0.1 \%$ surfactant alone, or distilled water and inoculated or not 2 days later by $P$. viticola $\left(10^{4}\right.$ sporangia/ml) were cut at different post-inoculation time points $(12,24,48$, or $72 \mathrm{~h})$, placed for $30 \mathrm{~min}$ in distilled water before transfer to DAB-HCl at $1 \mathrm{mg} / \mathrm{ml}$ as described by ThordalChristensen and associates (1997). Absorption and polymerization of DAB was confirmed by dark staining (reddishbrown) of the vascular tissues. Six hours later, foliar disks (1 $\mathrm{cm}$ in diameter) were excised and put into chloral hydrate solution $(2.5 \mathrm{mg} / \mathrm{ml})$ overnight at room temperature to clarify the host tissues. The foliar disks then were mounted on microscope slides in 50\% glycerol (aqueous solution) with the abaxial surface uppermost. $\mathrm{H}_{2} \mathrm{O}_{2}$ was visualized as a reddishbrown coloration.

\section{Observation of mycelium development in foliar tissues after aniline blue staining.}

Control or PS3-treated leaves inoculated by P. viticola were analyzed using a Leica microscope equipped with epifluorescence optics. Leaf disks ( $7 \mathrm{~mm}$ in diameter) were harvested at different times and incubated overnight in absolute methanol 
at room temperature. The samples then were transferred to chloral hydrate solution $(2.5 \mathrm{~g} / \mathrm{ml})$ overnight at room temperature to soften and clear the tissues. Cleared samples were incubated in $0.05 \%$ aniline blue (in $0.1 \mathrm{M}$ phosphate buffer, $\mathrm{pH}$ 8.0) overnight at room temperature. The foliar disks then were mounted on microscope slides in the staining solution, with the abaxial surface uppermost. Pathogen ingress was observed by epifluorescence microscopy under UV ( $\lambda_{\text {exc }} 340 \mathrm{~nm}, \lambda_{\text {em }}$ $380 \mathrm{~nm}$, stop filter LP $430 \mathrm{~nm}$ ). The mycelium fluoresces blue under these conditions.

\section{Tissue processing for scanning microscopy.}

Leaf disks ( $7 \mathrm{~mm}$ in diameter) were excised from grapevine plants and fixed with $2 \%$ glutaraldehyde (in $0.1 \mathrm{M}$ phosphate buffer, $\mathrm{pH}$ 7.2) during $1 \mathrm{~h}$ under vacuum, then overnight at $4^{\circ} \mathrm{C}$ with gentle rotation. Disks were washed three times in phosphate buffer, dehydrated in a graded ethanol series at $4^{\circ} \mathrm{C}$, critical point dried (Critical Point Dryer, Emscope CDP750, Ashford, Kent, England), and coated with gold. Samples were observed with a scanning electron microscope (Philips XL-30 ESEM LaB6).

\section{Leaf sampling for cytological analysis.}

For each treatment and each sampling date (3 or 6 dpi), fragments from nine independent leaves were embedded in either Epon (ultrastructural analysis) or LR White. The same number of uninoculated control or PS3-treated leaves was sampled and processed as the inoculated leaves. All samples were used for observation in both light and electron microscopy. For each leaf, sections were cut in three different zones along the foliar fragment and, for each zone, at least 60 sections were observed.

\section{Tissue processing for transmission electron microscopy.}

Leaf segments ( 2 by $5 \mathrm{~mm}$ ) were randomly excised and fixed immediately in $2.5 \%$ glutaraldehyde (in $0.1 \mathrm{M}$ sodiumcacodylate buffer, $\mathrm{pH} 7.2$ ) for 20 to $25 \mathrm{~min}$ under vacuum, then overnight at $4^{\circ} \mathrm{C}$ with gentle rotation. Samples were twice washed $(10 \mathrm{~min})$ in the same buffer and postfixed in $1 \%$ osmium tetroxide $\left(\mathrm{OsO}_{4}\right)$ in the same buffer for $1 \mathrm{~h}$ at $4^{\circ} \mathrm{C}$. Following osmium tetroxide fixation, samples were washed in cacodylate buffer, dehydrated in a graded ethanol series, and treated with propylene oxide. Dehydrated samples subsequently were embedded in Epon (Merck, Darmstadt, Germany) and sectioned using a Reichert Ultracut E microtome (Leica, Reuil-Malmaison, France) with glass or diamond knives (Diatome, Bienne, Switzerland). Semithin $(0.5 \mu \mathrm{m})$ sections from the tissue blocks were stained with $1 \%$ aqueous toluidine blue (in 1\% sodium tetraborate) and examined under a bright-field light microscope (Leica) in order to locate infection sites. Ultrathin $(90 \mathrm{~nm})$ sections of these areas were mounted on uncoated 300-mesh copper grids (Pelanne Instruments, Toulouse France), stained with uranyl acetate $(2.5 \%$ in methanol), followed by Reynold's lead citrate. Sections were examined using a Hitachi 600 electron microscope at an accelerating voltage of $75 \mathrm{kV}$.

\section{Leaf processing for observations under fluorescent and UV light.}

Leaf pieces ( 2 by $5 \mathrm{~mm}$ ) were fixed in $2 \%$ glutaraldehyde (in $0.1 \mathrm{M}$ sodium-cacodylate buffer, $\mathrm{pH}$ 7.2), dehydrated through an ethanol series and embedded in LR White resin (Oxford Instruments, Orsay, France), as described by Gianinazzi and Gianinazzi-Pearson (1992). Semithin and ultrathin sections were cut using a Reichert ultramicrotome as described above.

For fluorescent observations, the following filter combinations were used: A $\left(\lambda_{\mathrm{exc}} 340 / 380-\lambda_{\mathrm{em}} 425 \mathrm{~nm}\right)$ for UV excitation and I3 $\left(\lambda_{\text {exc }} 450 / 490-\lambda_{\text {em }} 515 \mathrm{~nm}\right)$ for blue excitation.
As controls, sequential sections were stained with toluidine blue as described above.

\section{RNA extraction and reverse transcription.}

Five leaf disks ( $1 \mathrm{~cm}$ in diameter) per treatment were ground in liquid nitrogen. Total RNA was isolated using Plant RNA purification reagent (Invitrogen, Carlsbad, CA, U.S.A.). Approximately $50 \mathrm{mg}$ of leaf powder was incubated with $0.5 \mathrm{ml}$ of Plant RNA purification reagent for $5 \mathrm{~min}$ at room temperature. After centrifugation at $12,000 \times g$ for $2 \mathrm{~min}, 100 \mu \mathrm{l}$ of 5 $\mathrm{M} \mathrm{NaCl}$ and $300 \mu \mathrm{l}$ of chloroform/isoamylic alcohol (24:1, $\mathrm{vol} / \mathrm{vol}$ ) were added to the supernatant. Samples were centrifuged for $10 \mathrm{~min}$ at $12,000 \times g$ at $4^{\circ} \mathrm{C}$. An equal volume of isopropanol was added to the aqueous phase. After incubation for $10 \mathrm{~min}$ at room temperature, samples were centrifuged for 10 $\min$ at $12000 \times g$ at $4^{\circ} \mathrm{C}$. The supernatant was removed and the pellet washed with $1 \mathrm{ml}$ of $75 \%$ ethanol. After centrifugation for $1 \mathrm{~min}$ at $12,000 \times g$, the supernatant was removed and the pellet air dried, then suspended in $30 \mu \mathrm{l}$ of distilled water.

RNAs (50 to $150 \mathrm{ng}$ ) were reverse-transcribed using the ABsolute MAX 2-step quantitative reverse-transcription (qRT)PCR SYBR green kit (Abgene, Epsom, U.K.) with a blend of random hexamers and anchored oligo-dT 3:1 as primers.

\section{Real-time qRT-PCR.}

The expression of six genes known to be involved in defense was analyzed in cv. Marselan plants (Table 1). RT-PCR was performed with Absolute qPCR SYBR Green Mix (ABgene) using an ABI Prism 5700 sequence detection system (Applied Biosystems). Specific primers were designed using the Primer Express software (Applied Biosystems, Foster City, CA, U.S.A.) (Table 1). PCR reactions were carried out in duplicate in 96-well plates in a volume of $25 \mu \mathrm{l}$ in a buffer containing $1 \times$ SYBR Green Mix (including Taq polymerase, dNTP, and SYBR Green dye), $300 \mathrm{nM}$ primers, and 50-fold diluted reverse-transcribed RNA. PCR conditions were $15 \mathrm{~min}$ at $95^{\circ} \mathrm{C}$ followed by 40 cycles each consisting of a step of denaturation: $15 \mathrm{~s}$ at $95^{\circ} \mathrm{C}$ and then a step of annealing and extension for $1 \mathrm{~min}$ at $60^{\circ} \mathrm{C}$. PCR efficiency for each target mRNA was controlled via the slope of a standard curve. The absence of primer-dimer formation was checked in no-template controls. Each time point was determined as an average from duplicates. Relative gene expression was determined with the formula fold induction $=2^{-\Delta \Delta \mathrm{Ct}}$, where $\Delta \Delta \mathrm{C}_{\mathrm{T}}=\left(\mathrm{C}_{\mathrm{T}}\right.$ GI [unknown sample] - $\mathrm{C}_{\mathrm{T}} \mathrm{GI}$ [reference sample] $)-\left(\mathrm{C}_{\mathrm{T}} \mathrm{EF} 1\right.$ [unknown sample] $\mathrm{C}_{\mathrm{T}} \mathrm{EF} 1$ [reference sample]). GI is the gene of interest. EF1, encoding the elongation factor 1 alpha, is used as internal control. The reference sample is the nontreated sample chosen to represent $1 \times$ expression of the gene of interest.

\section{Leaf disk assay with metabolic inhibitors.}

The callose synthase inhibitor DDG (Jakab et al. 2001) and the LOX inhibitor ETYA (Hamiduzzaman et al. 2005) were purchased from Sigma (St. Louis). The PAL inhibitor AIP (Zon and Amrhein 1992) was a gift from J. Zon (Wrocław University of Technology, Poland). AIP and DDG were dissolved in water and ETYA was dissolved in a few drops of ethanol prior to dissolving in water; they were used at concentrations of $1 \mathrm{mM}, 2 \mathrm{mM}$, and $20 \mu \mathrm{M}$, respectively, according to Hamiduzzaman and associates (2005).

Leaf disks (at least 10 by treatment) were floated (lower surface in contact with solution) on the chemical solutions during $24 \mathrm{~h}$. In the case of ETYA, the leaf disks were floated during only $2 \mathrm{~h}$. The leaf disks were rinsed in water and then transferred to petri dishes containing the second treatment (water, surfactant, or PS3 prepared at $2.5 \mathrm{mg} . \mathrm{ml}^{-1}$ in surfactant) during $24 \mathrm{~h}$. The leaf disks were rinsed in water and then transferred 
(lower surface uppermost) onto moist Whatman filter paper in a plexiglass box. They were inoculated immediately with a sporangial suspension of $P$. viticola $\left(10^{4}\right.$ sporangia. $\mathrm{ml}^{-1}$; one drop of $20 \mu \mathrm{l}$ per disk). The box containing the leaf disks then was placed in a $20^{\circ} \mathrm{C}$ growth chamber (16-h photoperiod) for the remaining time. At $5 \mathrm{dpi}$, the number of disks showing $P$. viticola sporulation was noted and an index of sporulation was scored on a scale of 0 to 5 , where $0=$ no visible sporulation, $1=$ 1 to $10 \%, 2=10$ to $25 \%, 3=25$ to $50 \%, 4=50$ to $75 \%$, and $5=$ 75 to $100 \%$ of the disk area covered. Data were subjected to LSD test. The experiment was carried out two times. Finally, all the disks were observed at a microscopic level after aniline blue staining.

\section{ACKNOWLEDGMENTS}

This study was performed within the framework of a Réseau Aliment Référence Europe project and founded by the French Research Ministry and Goëmar Laboratories. We thank J. Relot (CMAB, Dijon, France) for her technical assistance in scanning electron microscopy observations; $\mathrm{M}$. Adrian, J. Guern, and M. Nicole for helpful discussions; and J. Zon (Wrocław University of Technology, Poland) for kindly providing AIP.

\section{LITERATURE CITED}

Albersheim, P., and Darvill, A. 1985. Oligosaccharins. Sci. Am. 253:44-50.

Aziz, A., Poinssot, B., Daire, X., Adrian, M., Bezier, A., Lambert, B., Joubert, J.-M., and Pugin, A. 2003. Laminarin elicits defense responses in grapevine and induces protection against Botrytis cinerea and Plasmopara viticola. Mol. Plant-Microbe Interact. 16(12):1118-283.

Benhamou, N., Lafontaine, P. J., and Nicole, M. 1994. Induction of systemic resistance to Fusarium crown and root rot in tomato plants by seed treatment with chitosan. Phytopathology 84:1432-1444.

Carver, T. L. W., Zeyen, R. J., Robbins, M. P., Vance, C. P., and Boyles, D. A. 1994. Suppression of host cinnamyl alcohol dehydrogenase and phenylalanine ammonia lyase increases oat epidermal cell susceptibility to powdery mildew penetration. Physiol. Mol. Plant Pathol. 44:243-259.

Conrath, U., Beckers, G. J. M., Flors, V., Garcia-Agustin, P., Jakab, G., Mauch, F., Newman, M.-A., Pieterse, C. M. J., Poinssot, B., Pozo, M. J., Pugin, A., Schaffrath, U., Ton, J., Wendehenne, D., Zimmerli, L., and Mauch-Mani, B. 2006. Priming: Getting ready for battle. Mol. PlantMicrobe Interact. 19:1062-1071.

Côté, F., and Hahn, M.G. 1994. Oligosaccharins: Structures and signal transduction. Plant Mol. Biol. 26:1379-1411.

Côté, F., Ham, K.-S., Hahn, M. G., and Bergmann, C. W. 1998. Oligosaccharide elicitors in host-pathogen interactions: Generation, perception, and signal transduction. Pages 385-432 in: Cellular BiochemistryPlant-Microbe Interactions, Vol. 29. B. B. Biswas and H. Das, eds. Plenum Publishing Corp., New York.

Garcia-Brugger, A., Lamotte, O., Vandelle, E., Bourque, S., Lecourieux, D., Poinssot, B., Wendehenne, D., and A. Pugin. 2006. Early signaling events induced by elicitors of plant defenses. Mol. Plant-Microbe Interact. 19(7):711-24

Gianinazzi, S., and V. Gianinazzi-Pearson. 1992. Cytology, histochemistry and immunocytochemistry as a tool for studying structure and function in endomycorrhiza. Methods Microbiol. 24:109-139.

Gindro, K., Pezet, R., and Viret, O. 2003. Histological studies of responses of two Vitis vinifera cultivars (resistant and susceptible) to Plasmopara viticola infections. Plant Physiol. Biochem. 41(9):846-853.

Hamiduzzaman, M. M., Jakab, G., Barnavon, L., Neuhaus, J. M., and Mauch-Mani, B. 2005. $\beta$-Aminobutyric acid-induced resistance against downy mildew in grapevine acts through the potentiation of callose formation and jasmonic acid signaling. Mol. Plant-Microbe Interact. 18:819-829.

Hu, G. G., Linning, R., and Bakkeren G. 2003. Ultrastructural comparison of a compatible and incompatible interaction triggered by the presence of an avirulence gene during early infection of the smut fungus, Ustilago hordei, in barley. Physiol. Mol. Plant Pathol. 62(3):155-166.

Jakab, G., Cottier, V., Toquin, V., Rigoli, G., Zimmerli, L., Metraux, J.-P., and Mauch-Mani, B. 2001. Beta-amminobutyric acid-induced resistance in plants. Eur. J. Plant Pathol. 107:29-37.

Jones, D. G., and Dangl J. L. 2006. The plant immune system. Nature 444:323.

Klarzynski, O., Plesse, B., Joubert, J.-M., Yvin, J. C., Kopp, M., Kloareg, B., and Fritig, B. 2000. Linear beta-1,3 glucans are elicitors of defense responses in tobacco. Plant Physiol. 124(3):1027-1038.

Langcake, P., and Lovell, P. A. 1980. Light and electron microscopical studies of the infection of Vitis spp. by Plasmopara viticola, the downy mildew pathogen. Vitis 19:321-337.

Levine, A., Tenhaken, R.., Dixon, R.., and Lamb C. 1994. $\mathrm{H}_{2} \mathrm{O}_{2}$ from the oxidative burst orchestrates the plant hypersensitive disease resistance response. Cell 79(4):583-93.

Mellersh, D. G., Foulds, I. V., Higgins, V. J., and Heath, M. C. 2002. $\mathrm{H}_{2} \mathrm{O}_{2}$ plays different roles in determining penetration failure in three diverse plant-fungal interactions. Plant J. 29(3):257-68.

Ménard, R., Alban, S., de Ruffay, P., Jamois, F., Franz, G., Fritig, B., Yvin, J.-C., and Kaufmann, S. 2004. $\beta-1,3$ Glucan sulfate, but not $\beta-1,3$ glucan, induces the salicylic acid signaling pathway in tobacco and Arabidopsis. Plant Cell 16 (11):3020-3032.

Métraux, J.-P. 2002. Recent breakthroughs in the study of salicylic acid biosynthesis. Trends Plant Sci. 7(8):332-334.

Nürnberger, T., Brunner, F., Kemmerling, B., and L. Piater. 2004. Innate immunity in plants and animals: Striking similarities and obvious differences. Immunol. Rev. 198:249-266.

Olson, P. D., and Varner, J. E. 1993. Hydrogen peroxide and lignification. Plant J. 4:887-892.

Poinssot, B., Vandelle, E., Bentéjac, M., Adrian, M., Levis, C., Brygoo, Y., Garin, J., Sicilia, F., Coutos-Thévenot, P., and Pugin, A. 2003. The endopolygalacturonase 1 from Botrytis cinerea activates grapevine defense reactions unrelated to its enzymatic activity. Mol. Plant-Microbe Interact. 16(6):553-564.

Pugin, A., Frachisse, J. M., Tavernier, E., Bligny, R., Gout, E., Laurière, C., and Guern, J. 1997. Early events induced by the elicitor cryptogein in tobacco cells: Involvement of a plasma membrane NADPH oxidase and activation of glycolysis and the pentose phosphate pathway. Plant Cell. 9:2077-2091.

Sergeeva, V., Nair, N., Legendre, L., Darley, E., and Spooner-Hart, R. 2002. The use of fluorochromes to determine the effect of chlorine dioxide on survival of Plasmopara viticola on grapevine. Australas. Plant Pathol. 31:295-297.

Sharp, J. K., Valent, B., and Albersheim, P. 1984. Purification and partial characterization of a $\beta$-glucan fragment that elicits phytoalexin accumulation in soybean. J. Biol. Chem. 259:11312-11320.

Sheel, D. 1998. Resistance response physiology and signal transduction. Curr. Opin. Plant Biol. 1(4):305-310.

Soylu, E. M., Soylu, S., and Mansfield, J. W. 2004. Ultrastructural characterisation of pathogen development and host responses during compatible and incompatible interactions between Arabidopsis thaliana and Peronospora parasitica. Physiol. Mol. Plant Pathol. 65:67-78.

Thordal-Christensen, H., Zhang, Z., Wei, Y., and Collinge, D. B. 1997. Subcellular localization of $\mathrm{H}_{2} \mathrm{O}_{2}$ in plants. $\mathrm{H}_{2} \mathrm{O}_{2}$ accumulation in papillae and hypersensitive response during the barley-powdery mildew interaction. Plant J. 11(6):1187-1194.

Torres, A. T., Jones J. D. G., and Dangl J. L. 2006. Reactive oxygen species signaling in response to pathogens. Plant Physiol. 141:373-378.

Vandelle, E., Poinssot, B., Wendehenne, D., Bentéjac, M., and Pugin, A. 2006. Integrated signaling network involving calcium, nitric oxide, and active oxygen species but not mitogen-activated protein kinases in BcPG1-elicited grapevine defenses. Mol. Plant-Microbe Interact. 19(4):429-440.

Van Hulten, M., Pelser, M., van Loon, L. C., Pieterse, C. M. J., and Ton, J. 2006. Costs and benefits of priming for defense in Arabidopsis. Proc. Natl. Acad. Sci. U.S.A. 103(14):5602-5607.

Zon, J., and Amrhein, N. 1992. Inhibitors of phenylalanine ammonialyase: 2-aminoindan-2-phosphonic acid and related compounds. Liebigs Ann. Chem. 6:625-628. 